\title{
REPERCUSSÕES NA VIDA DE CUIDADORES DE CRIANÇAS E ADOLESCENTES COM DOENÇA ONCOLÓGICA
}

\author{
Juliana da Silva Oliveira', Danielle de Oliveira Cunha², Charles Souza Santos ${ }^{3}$, \\ Roberta Laíse Gomes Leite Morais ${ }^{4}$
}

RESUMO: Objetivo: descrever as repercussões que ocorreram na vida de cuidadores de crianças e adolescentes com doença oncológica. Método: estudo descritivo com abordagem qualitativa, realizado entre maio e junho de 2015, com 15 cuidadores de crianças e adolescentes, em uma instituição de apoio a crianças com câncer de um município da região sul da Bahia. Os dados foram coletados através de entrevistas semiestruturadas e analisados conforme a técnica de análise de conteúdo, modalidade temática. Resultados: identificou-se como dificuldades para as cuidadoras as mudanças da rotina familiar e os problemas financeiros, e como facilidade o apoio encontrado. Os principais sentimentos vivenciados pelas mesmas foram desânimo, tristeza, perda, revolta, vitória, morte e fé. Conclusão: dessa forma, faz-se necessário acompanhamento com equipe multidisciplinar, a fim de fornecer o suporte emocional para as cuidadoras poderem vivenciar as repercussões que o processo de cuidar thes impõe.

DESCRITORES: Neoplasias; Cuidadores; Crianças; Adolescentes.

\section{IMPACT OF CARING FOR CHILDREN AND ADOLESCENTS WITH CANCER ON THE QUALITY OF LIFE OF CAREGIVERS}

ABSTRACT: Objective: to describe the impacts of caring for children and adolescents with cancer on the lives of caregivers. Method: Descriptive study with a qualitative approach conducted from May to June 2015. Fifteen (15) caregivers of children and adolescents from an institution that provides support to children with cancer in a municipality in the southern region of Bahia. The data were collected through semi-structured interviews and analyzed according to the technique of content analysis, thematic modality. Results: Changes in family routine and financial problems were identified as negative aspects faced by caregivers, and the support obtained was identified as a positive aspect. The main feelings experienced by them were discouragement, sadness, loss, revolt, victory, death and faith. Conclusion: It can be concluded that follow up by a multidisciplinary team is necessary to provide emotional support to caregivers, in order to prepare them to cope with the stressful events associated with the care process.

KEYWORDS: Neoplasias; Caregivers; Children; Adolescents.

\section{REPERCUSIONES EN LA VIDA DE CUIDADORES DE NIÑOS Y ADOLESCENTES CON ENFERMEDAD ONCOLÓGICA}

RESUMEN: Objetivo: describir las repercusiones que ocurrieron en la vida de cuidadores de niños y adolescentes con enfermedad oncológica. Método: estudio descriptivo con abordaje cualitativo, hecho entre mayo y junio de 2015, con 15 cuidadores de niños y adolescentes, en una institución de apoyo a niños con cáncer de un municipio de la región sur de Bahia. Se obtuvieron los datos por medio de entrevistas semi estructuradas y se los analizaron conforme la técnica de análisis de contenido, modalidad temática. Resultados: se identificaron como dificultades para las cuidadoras los cambios de la rutina familiar y los problemas financieros, y como facilidad el apoyo encontrado. Los principales sentimientos presentes fueron desánimo, tristeza, pérdida, indignación, vitoria, muerte y fe. Conclusión: es necesario acompañamiento con el equipo multidisciplinar, con fines de fornecer el suporte emocional para que las cuidadoras puedan vivir las repercusiones que el proceso de cuidar les impone.

DESCRIPTORES: Neoplasias; Cuidadores; Niños; Adolescentes.

Enfermeira. Doutoranda em Enfermagem e Saúde. Docente do Departamento de Saúde II da Universidade Estadual do Sudoeste da Bahia. Jequié-BA-Brasil.

${ }^{2}$ Enfermeira. Graduada pela Universidade Estadual do Sudoeste da Bahia. Jequié-BA-Brasil.

${ }^{3}$ Enfermeiro. Doutorando em Enfermagem. Docente do Departamento de Saúde II da Universidade Estadual do Sudoeste da Bahia. Jequié-BA-Brasil.

${ }^{4}$ Enfermeira. Mestre em Enfermagem e Saúde. Docente do Departamento de Saúde II da Universidade Estadual do Sudoeste da Bahia. Jequié-BA-Brasil. 


\section{INTRODUÇÃO}

O Instituto Nacional de Câncer - INCA denomina o câncer como um "conjunto de mais de 100 doenças, tendo em comum o crescimento desordenado de células, que tendem a invadir tecidos e órgãos vizinhos"(1:17). Devido aos elevados índices de morbidade e mortalidade dos indivíduos com essa patologia, a confirmação desse diagnóstico é quase sempre associada com a morte ${ }^{(2)}$, fazendo com que seja difícil de ser abordada e enfrentada.

Com o intuito de minimizar o fardo terapêutico e o perigo de futuras sequelas, torna-se necessário identificar o tipo de câncer no estágio inicial da doença, objetivando adotar a melhor intervenção. O estágio do câncer e o tipo de tecido lesionado pelo tumor serão definidores para recidiva e a mortalidade. Os pontos desfavoráveis mais relevantes são estadiamentos avançados e a má formação de uma célula ou tecido, principalmente quando a quimioterapia não alcança mais o recurso almejado ${ }^{(3)}$.

Esta doença é caracterizada por ser dolorosa não apenas para os diagnosticados, mas também para os familiares e/ou cuidadores que vivenciam o processo de adoecimento. Em crianças/adolescentes, essa abordagem se torna ainda mais complexa, devido aos períodos prolongados e frequentes de hospitalização, o que pode gerar interrupções das atividades rotineiras.

Diversas são as repercussões da doença oncológica na vida dos pacientes. Acredita-se que para o êxito no tratamento é necessário que ocorra a aceitação da condição atual de vida, e a família é a fundamental rede de apoio social da criança/adolescente, devido ao fato de ser indispensável para o enfrentamento da doença ${ }^{(4)}$. $\mathrm{O}$ ato de cuidar constitui-se em uma difícil tarefa para cuidadores que precisarão de apoio para o enfretamento das novas mudanças determinadas pelo diagnóstico de câncer.

A família que vivencia uma doença oncológica necessita de atenção integral, já que ocorre sobrecarga que é imposta para ela referente aos cuidados que deverão ser prestados ao doente ${ }^{(5)}$.

Sabe-se da relevância da participação dos cuidadores no acompanhamento e tratamento de crianças/ adolescentes com doença oncológica. Contudo, existem poucos estudos que visam a identificar as repercussões que ocorrem na vida destes, haja vista que poderão ter modificações em suas atividades diárias, em decorrência das diversas atribuições que requer o cuidado a esses indivíduos.

A complexidade do cuidar de pacientes com câncer fomentou este estudo que tem por objetivo descrever as repercussões que ocorreram na vida dos cuidadores de crianças/ adolescentes com doença oncológica. Desta forma, compreende-se que a atenção em saúde necessita ir além das demandas físicas do paciente, devendo, portanto, compreender as necessidades psicológicas e sociais vivenciadas por aqueles que o cuidam.

\section{○ MÉTODO}

O estudo é caracterizado como pesquisa de abordagem descritiva e qualitativa. O delineamento do estudo contempla o objeto, visto que se trata de experiências, sentimentos e influências vivenciadas pelos sujeitos que aqui foram pesquisados ${ }^{(6)}$.

Este estudo foi realizado em uma instituição de apoio a crianças com câncer, que fica situado no município de Itabuna, localizado na região do sul da Bahia, entre os meses de maio e junho de 2015. Os informantes foram 15 cuidadores de crianças e adolescentes portadores de doença oncológica.

Os critérios de elegibilidade no estudo foram: ser cuidadores de crianças/adolescentes com doença oncológica; estar na instituição no momento da coleta. Foram excluídos os cuidadores que não se encontravam na instituição após três visitas. Para a realização da coleta de dados, foram utilizadas as entrevistas semiestruturadas, as quais foram gravadas com a finalidade de manter a fidedignidade das informações, transcritas na íntegra e posteriormente comparadas com a gravação. 
Os dados foram analisados através da técnica de análise de conteúdo, modalidade temática. Assim, a análise obedeceu às fases de pré-análise, constituição do corpus, seleção das unidades de significância, classificação e agregação dos núcleos temáticos ${ }^{(7)}$.

O estudo obedeceu à Resolução n. 466/2012, que dispõe sobre as Diretrizes e Normas Regulamentares na Pesquisa com Seres Humanos ${ }^{(8)}$, sendo submetido ao Comitê de Ética em Pesquisa da Universidade Estadual do Sudoeste da Bahia - CEP/UESB, e aprovado sob o parecer n. 1.048.119.

\section{RESUltados}

A amostra elegível do estudo foi composta por 15 cuidadoras de crianças e adolescentes, entre 27 e 63 anos, mulheres, com filhos, sete $(46,6 \%)$ tinham união estável, 12 (80\%) eram do lar e com renda familiar entre $\mathrm{R} \$ 120,00$ e $\mathrm{R} \$ 788,00$.

Das análises dos depoimentos, emergiram duas categorias principais de investigação: "Facilidades e dificuldades vivenciadas pelas cuidadoras" e "Sentimentos vivenciados pelas cuidadoras".

\section{Categoria 1 - Facilidades e dificuldades vivenciadas pelas cuidadoras}

Vários são os fatores que podem influenciar no cuidado às crianças e aos adolescentes com doença oncológica e na vida de suas cuidadoras. Nesse sentido, esta categoria apresenta unidades de análise que relatam um ponto facilitador citado no enfretamento da doença. Contudo, foi observada a existência de diversas dificuldades, desde questões financeiras a relacionamento familiar.

A única facilidade relatada foi o apoio. Sabe-se que este é essencial para que o indivíduo e o cuidador consigam enfrentar a nova fase que terão que vivenciar.

As médicas foram me dando conselho e eu me conformei mais. (E. 11)

Aí os parentes ajudaram bastante, a gente teve muito apoio. (E. 14)

Por outro lado, diversas foram as dificuldades mencionadas pelos participantes deste estudo. Percebese que o impacto do diagnóstico pode causar desestruturação no âmbito familiar, sendo que o processo do adoecimento compromete o cotidiano de todos os envolvidos com a enfermidade.

[...] é porque no meu caso a rotina muda muito, que ela tem que tá aqui... eu tenho que deixar as coisas porque no momento eu tenho que cuidar só dela; às vezes, eu falo assim: nossa eu tenho que cuidar um pouco de mim. (E. 12)

No ambiente familiar mudou tudo, porque, desde que a gente descobriu, é difícil ficar em casa, vou pra Salvador, volto pra aqui pra Itabuna, já fiquei 2 meses lá em Salvador... aí afeta toda estrutura. (E. 13)

Outra condição imposta às cuidadoras, pelo processo de adoecimento, foi a necessidade de deixar a família/lar para realizar o cuidado com o doente.

É difícil a gente deixar marido pra trás, casa pra trás, mas eu prefiro cuidar do meu filho. (E. 04)

[...] viver isso tudo e ainda longe da família, o pior pra mim foi isso... eu tive que mudar tudo, deixar tudo pra trás, deixar casa, deixar marido, deixar família, deixar o trabalho. (E. 05)

Deixei de trabalhar pra cuidar dele, abandonei também minha casa. (E. 07)

Ainda como dificuldade, foi mencionada a falta do apoio familiar e relacionamento conjugal.

Não gosto nem de falar [choro]... apoio mesmo na família eu não tive... foi afastando o pessoal... e eu acabei sozinha, fiquei sozinha com ela... (E. 02) 
Além disso, depois de tudo... meu marido estava com outra pessoa ... eu fiquei assim desolada... (E. 03)

A falta do lazer foi outra dificuldade identificada a partir das unidades de análise, tendo em vista que as cuidadoras deixaram de realizar ou, atualmente, já não fazem com tanta frequência como anteriormente.

[...] não tenho ânimo mais de sair, aí minha rotina é só dentro de casa, só saio pra aqui quando eu venho trazer ela pra o médico. (E. 02)

Saía sempre, ia pra casa de minha tia, pra casa de minha mãe, que ela mora na roça, mas hoje não vou mais. (E. 03)

A dificuldade financeira emerge como um importante fator vivenciado por algumas cuidadoras.

A dificuldade lá em casa é que, porque ele [marido] não podia trabalhar pra mandar nenhum dinheiro pra mim... (E. 03)

[...] a gente não tinha condições pra vim pra cá, ela ficou internada no hospital esperando transferir, porque não podia sair de lá pra vim pra cá por conta própria. (E. 15)

Associado à condição financeira, a dependência do transporte municipal foi outra dificuldade relatada pelas cuidadoras.

[...] a dificuldade, assim, devido ao carro, tem vez até que vêm buscar nós, tem vez que não vem, e a gente tem que ficar aqui. (E. 01)

\section{Categoria 2 - Sentimentos vivenciados pelas cuidadoras}

Quando questionadas sobre os sentimentos que emergiram no momento da descoberta do diagnóstico, as cuidadoras relataram que diversos, a saber: morte, desânimo, tristeza, revolta, questionamento, vitória e em todo momento se percebe a ênfase que foi expressa pelas questões religiosas e espirituais.

A morte apresenta-se como um dos relatos mais mencionados pelas cuidadoras.

Fiquei com muita pena, chorei demais, eu pensei que naquele momento eu ia perder ele... (E. 04)

Senti meu chão abrir, pra mim nada mais fazia sentido; a gente pensa logo na morte, não pensa nem na cura, no primeiro momento a gente já pensa assim: é o fim, vai morrer. (E. 05)

Observa-se que sentimentos como tristeza, culpa, desespero, medo, insegurança, angústia e raiva também foram mencionados pelas cuidadoras por estarem vivenciando esse momento doloroso, que é conviver com a doença oncológica.

Eu senti muito triste... foi um gelo que veio dentro de mim, aquele susto que eu tomei, aí só foi mesmo chorar... (E. 10)

Fiquei triste e com raiva, até de mim mesmo, porque tinha vezes que ele se queixava da dor e eu pensava que era bobagem. (E. 13)

Sentimentos como esperança, fé e espiritualidade foram destacados pelas cuidadoras.

Fui rezando também, pedindo a Deus força para conseguir vencer e aí, mais ou menos com uns seis meses, eu fui me acalmando... aquela multidão de gente... fazia oração e tudo. (E. 02)

Graças a Deus, eu superei. (E. 07)

Eu passei um difícil momento que só Deus pra segurar a gente... (E. 08) 
Dessa forma, observa-se que diversos são os sentimentos vivenciados pelos cuidadores que acompanham crianças/adolescentes da doença oncológica, sendo necessário acompanhamento de equipe multiprofissional para ajudá-los no enfrentamento dessa situação.

\section{DISCUSSÃO}

Os resultados desse estudo demonstram que os cuidadores de crianças e adolescentes em tratamento de câncer foram apenas mulheres, que em sua maioria assumem esse papel social. Um estudo realizado com mulheres cuidadoras evidenciou que, geralmente, são as mães pobres as que possuem dificuldades para manter-se ou se inserir no mercado de trabalho e que vivenciam um contexto de doença grave na família ${ }^{(9-10)}$.

O apoio encontrado no ambiente e nas pessoas fez com que as cuidadoras tivessem respostas mais adaptativas para conviverem com o tratamento oncológico dos seus filhos. Esses resultados se assemelham com um estudo realizado em Goiânia ${ }^{(4)}$. Neste contexto, a equipe de enfermagem e a equipe multidisciplinar, através da vivência com os cuidadores, possuem papel relevante com vistas a facilitar a inclusão e participação da família no cuidado ${ }^{(11)}$, bem como compreender o momento de modificações da rotina diária que acontece na vida dos cuidadores ${ }^{(9)}$.

Grande parte dos familiares sofre alterações nas rotinas domésticas devido à hospitalização e ao sofrimento gerado pela convivência limitada, ocasionando a desestruturação familiar ${ }^{(12)}$. O adoecer é um processo difícil e que impõe ao paciente diversas mudanças, devido a sua gravidade, perdas e ou afastamento das rotinas, que, por vezes, geram conflitos no ambiente familiar ${ }^{(4,13-14)}$. Nesta pesquisa, os participantes relataram que desde o momento do diagnóstico houve modificações na estrutura familiar, como, por exemplo, o afastamento do lar e dos demais membros da família.

Corroborando com os achados desse estudo, salienta-se que mudanças na vida dos cuidadores podem ser percebidas através da diminuição do convívio social, redução das atividades de lazer com as famílias, amigos, e outras redes, tais como igreja, escola e vizinhos ${ }^{(4,13)}$. Contudo, sabe-se que a prática do lazer é essencial para o bem estar psíquico e físico do indivíduo.

Além disso, o tratamento da doença oncológica exige dedicação do cuidador, o que pode resultar no afastamento do local onde vive, necessitando adaptar-se ao novo. Este é um momento em que muitas deles vivenciam um conflito em ter que abandonar o lar, principalmente por terem outros filhos e companheiro.

A sensação de abandono é recorrente, tanto no que se refere a sentirem-se sozinhas, desamparadas, quanto à culpa de terem que abandonar suas casas, maridos e outros filhos ${ }^{(4)}$. De um modo geral, o adoecimento altera o padrão do funcionamento familiar. Contudo, a mãe, frequentemente, se sente na obrigação de prestar o cuidado integral ao filho ${ }^{(11)}$. Os resultados da pesquisa demonstraram que as cuidadoras preferiam realizar o cuidado integral aos seus filhos, independentemente das consequências que poderiam repercutir na estrutura familiar.

Sabe-se da relevância do apoio da família para garantir melhor recuperação das crianças/adolescentes que se encontram em enfermidade, tal como narrado pelos participantes da pesquisa, como dedicação, tempo, recursos financeiros, modificação da rotina diária, entre outros, fazendo com que seja necessária comunhão de todos na tomada de decisão e diálogo para o enfrentamento dos conflitos, visando a satisfazer as necessidades mútuas daqueles envolvidos no processo de adoecimento.

Apesar de algumas cuidadoras referirem ter encontrado apoio após o diagnóstico e durante o tratamento do câncer, esta não foi a realidade observada na maioria das unidades de análise. Percebese que a relação entre a família é bastante complexa e que, muitas vezes, a mesma se mostrou distante e pouco solícita em se envolver com a situação de doença. 
Muitas cuidadoras desta pesquisa acabam se dedicando integralmente ao cuidado com o enfermo, e o companheiro parece não entender o motivo pelo qual a sua parceria se afasta do lar e do seu não envolvimento, como antes, com os afazeres domésticos.

Estudos abordam que a relação conjugal, por vezes, modifica-se, pois menos atenção é fornecida ao companheiro, o que gera a intensificação, as cobranças e os conflitos. As relações sexuais também se tornam menos frequentes, tendo como consequência a separação para alguns casais que não superam esse momento ${ }^{(9-12)}$.

Confirmando o que foi referido por participantes da pesquisa, autores afirmam que o fato de não ter com quem dividir o cuidado com o paciente e os afazeres domésticos, leva a maioria das cuidadoras a perder o emprego, o que contribui para conviver com as dificuldades financeiras ${ }^{(5,10)}$. Ainda existe a necessidade de realizar rearranjo em situações rotineiras, como a modificação na situação econômica e na dinâmica familiar ${ }^{(15)}$.

Assim, a dificuldade financeira emerge como um importante fator vivenciado por algumas cuidadoras desta pesquisa, já que muitas destas têm que deixar o emprego ou outras atividades remuneradas para cuidar das crianças ou dos adolescentes que vivenciam a situação oncológica, passando a depender da ajuda e/ou benefício do governo, ajuda da família, dos amigos e da comunidade para sobreviver.

Porém, por mais que esta dificuldade esteja presente na vida das cuidadoras, elas têm clara a necessidade de dedicar seu tempo ao cuidado, mesmo que para isso precisem abdicar de sua vida pessoal. Também, percebe-se que os parceiros das cuidadoras também tiveram que mudar a sua rotina.

O transporte foi outra dificuldade vivenciada, pois para a realização do tratamento, os pacientes e suas cuidadoras necessitavam se deslocar de cidade, já que no município onde residiam não possuía local apropriado para seu cuidado e não proporcionava regularmente condições para o deslocamento. Isso gera grande desgaste físico e financeiro para ambos, trazendo repercussões no seu dia a dia.

A Portaria Ministerial n. 55 de 24 de fevereiro de 1999 dispõe sobre a obrigatoriedade que o Município/ Estado possui em custear o tratamento de indivíduos que não possuem condições de realizá-lo ${ }^{(16)}$. Evidencia-se, através das unidades de análises, que o referido município não tem garantido plenamente esse direito para tal população.

Além disso, as diversas atribuições exigidas para os cuidadores repercutem nos aspectos da sua vida, tanto no âmbito pessoal, familiar e laboral quanto no social, o que poderá levá-los a conflitos no seu cotidiano, refletindo na sua qualidade de $v \mathrm{ida}^{(5)}$. Por mais que as dificuldades influenciem na vida das cuidadoras, estas fazem o possível para superá-las e conseguir adaptar-se ao novo, buscando vencer as barreiras impostas pela condição do adoecimento.

Corroborando com os achados desse estudo, atinente aos sentimentos vivenciados, constata-se que outras pesquisas abordam a presença da morte como sendo um dos principais sentimentos que os cuidadores vivenciam durante o processo do adoecimento decorrente do câncer. $O$ fato de conviver com a eminência da morte os expõe aos mais diversos sentimentos ${ }^{(4,17-18)}$.

Percebe-se que o desespero é um sentimento que se encontra no processo de enfrentamento do câncer desde sua descoberta, especialmente quando se trata de patologia com vários relatos negativos e marcado por inúmeras histórias pessoais, familiares e culturais movidas pela tristeza, solidão e sensação de fracasso $^{(18)}$.

Durante o processo de enfrentamento do câncer, os sentimentos mais comuns vivenciados pelos familiares estão relacionados com o choque, o desespero, o susto, a revolta e a angústia, responsáveis por gerar modificações na vida dos cuidadores dos pacientes com câncer ${ }^{(4,18)}$.

Entretanto, as vivências espirituais se relacionam com a procura de respostas para o sofrimento e questionamentos existenciais da doença. Desse modo, incentivam o cuidador e a criança a focalizarem a atenção na esperança, despertando neles coragem para lidar e conviver com os problemas relacionados com a patologia ${ }^{(12)}$. 
Nessa pesquisa, notou-se que as cuidadoras relataram diversas dificuldades e sentimentos, e que mesmo em meio à dor elas obtêm na espiritualidade o apoio necessário para continuar na busca da recuperação e reabilitação da criança/adolescente. A espiritualidade proporciona força para superar, dá coragem, minimiza o sofrimento, além de ajudar na adaptação e adesão ao tratamento ${ }^{(19)}$.

Assim, faz-se necessária a existência de suporte local, garantido a sua manutenção pelo Estado/ Município, por meio de equipe multiprofissional, tanto para o paciente diagnosticado com câncer, como para as cuidadoras que vivenciam mudanças em suas atividades diárias da vida, devido às diversas repercussões que são experenciadas com a nova condição imposta pelas circunstâncias da vida, principalmente para aquelas que já estão no processo de cuidar a mais tempo.

Esse estudo apresenta como limitação o fato de não ter realizado a análise da informação referente ao tempo em que as cuidadoras estão desenvolvendo essa função, já que esse dado pode interferir nas repercussões vivenciadas por elas.

\section{CONCLUSÃO}

Diante do exposto, foi possível concluir que a doença oncológica interfere de forma significativa na qualidade de vida das cuidadoras, sendo necessário acompanhamento contínuo durante o processo de tratamento e reabilitação, visto que as fragilidades e inseguranças das cuidadoras irão refletir no tratamento das crianças e dos adolescentes.

Além disso, observou-se que ocorreu modificação na rotina e nos hábitos de vida diários das cuidadoras. Como forma de alcançar a superação do sofrimento, imposto pelo processo de adoecimento, muitas vezes, elas buscam as questões espirituais e religiosas.

Acredita-se que esse estudo possa contribuir para ampliar o conhecimento dos profissionais da área de saúde sobre as repercussões vivenciadas por cuidadoras, demonstrando a necessidade de acompanhamento para as mesmas, haja vista que são peças essenciais para a realização e conclusão do tratamento nessa população.

Portanto, faz-se necessário realizar abordagem pela equipe multidisciplinar, a fim de garantir suporte emocional para as cuidadoras poderem vivenciar os diversos sentimentos e repercussões que a doença Ihes impõe, compreendendo que essa cuidadora está inserida em um contexto social e precisa ser vista em sua totalidade e integralidade, com seus medos, incertezas, dúvidas e sentimentos.

\section{REFERÊNCIAS}

1. Ministério da Saúde (BR). Secretaria de Atenção à Saúde. Instituto Nacional de Câncer - INCA. ABC do câncer: abordagens básicas para o controle do câncer. [Internet] Rio de Janeiro: Ministério da Saúde/INCA; 2011 [acesso em 05 ago 2017]. Disponível: http://bvsms.saude.gov.br/bvs/publicacoes/abc_do_cancer.pdf.

2. Regis MF, Simões MFS. Diagnóstico de câncer de mama, sentimentos, comportamentos e expectativas de mulheres. Rev. Eletr. Enf. [Internet] 2005;7(1) [acesso em 03 out 2017]. Disponível: https://www.fen.ufg.br/fen_revista/revista7_1/original_08.htm.

3. Provenzi VO, Rosa RFM, Rosa RCM, Roehe AV, dos Santos PPA, Faulhaber FRS, et al. Tamanho tumoral e prognóstico em pacientes portadores de tumor de Wilms. Rev. paul. pediatr. [Internet] 2015;33(1) [acesso em 05 out 2016]. Disponível: http://dx.doi.org/10.1016/j.rpped.2014.05.003.

4. Vinhal LM, Costa Neto SB. Aspectos psicológicos de mães de crianças em tratamento oncológico. Revista Saúde e Desenvolvimento Humano. [Internet] 2013;1(1) [acesso em 20 out 2016]. Disponível: https://revistas.unilasalle.edu.br/ index.php/saude_desenvolvimento/article/view/1011/0. 
5. de Toledo MO, Ballarin MLGS. Qualidade de vida: cuidadores informais de pacientes em tratamento quimioterápico. Rev. Ciênc. Méd. [Internet] 2013;22(1) [acesso em 07 nov 2016]. Disponível: http://periodicos.puc-campinas.edu.br/ seer/index.php/cienciasmedicas/article/view/1997.

6. Minayo MCS. O desafio do conhecimento: pesquisa qualitativa em saúde. 12ª ed. Rio de Janeiro: Hucitec; 2010.

7. Bardin L. Análise de conteúdo. Lisboa: Edições 70; 2010.

8. Ministério da Saúde (BR). Conselho Nacional de Saúde. Diretrizes e normas regulamentadoras de pesquisa envolvendo seres humanos. Resolução n. 466, de 12 de dezembro de 2012. Brasília; 2012.

9. Wegner W, Pedro ENR. Os múltiplos papéis sociais de mulheres cuidadoras-leigas de crianças hospitalizadas. Rev. Gaúcha Enferm. [Internet] 2010;31(2) [acesso em 04 out 2017]. Disponível: http://dx.doi.org/10.1590/S198314472010000200019 .

10. Santo EARE, Gaíva MAM, Espinosa MM, Barbosa DA, Belasco AGS. Cuidando da criança com câncer: avaliação da sobrecarga e qualidade de vida dos cuidadores. Rev. Latino-Am. Enfermagem. [Internet] 2011;19(3) [acesso em 10 nov 2016]. Disponível: http://dx.doi.org/10.1590/S0104-11692011000300010.

11. Alves KMC, Comassetto I, de Almeida TG, Trezza MCSF, de Oliveira e Silva JM, de Magalhães APN. A vivência dos pais da criança com câncer na condição de impossibilidade terapêutica. Texto contexto - enferm. [Internet] 2016;25(2) [acesso em 17 dez 2017]. Disponível: http://dx.doi.org/10.1590/0104-07072016002120014.

12. de Araujo PCB, Dantas MMC, Lopes SSM, Morais D, de Oliveira LCB, Maia EMC. Os impactos na vida dos cuidadores de criança com câncer: uma revisão de literatura. Perspectivas en psicología. [Internet] 2013;10(4) [acesso em 15 nov 2016]. Disponível: http://www.seadpsi.com.ar/revistas/index.php/pep/article/view/130.

13. Sanches MVP, Nascimento LC, de Lima RAG. Crianças e adolescentes com câncer em cuidados paliativos: experiência de familiares. Rev. bras. enferm. [Internet] 2014;67(1) [acesso 17 dez 2017]. Disponível: http://dx.doi. org/10.5935/0034-7167.20140003.

14. dos Santos EM, Sales CA. Familiares enlutados: compreensão fenomenológica existencial de suas vivências. Texto contexto - enferm. [Internet]. 2011;20(n. esp) [acesso em 01 set 2015]. Disponível: http://dx.doi.org/10.1590/S010407072011000500027.

15. da Encarnação JF, Farinasso ALC. A família e o familiar cuidador de pacientes fora de possibilidades terapêuticas: uma revisão integrativa. Semina: Ciências Biológicas e da Saúde. [Internet] 2014;35(1) [acesso em 05 ago 2017]. Disponível: http://dx.doi.org/10.5433/1679-0367.2014v35n1p137.

16. Ministério da Saúde. Portaria no 55, de 24 de fevereiro de 1999. Dispõe sobre a rotina do Tratamento Fora de Domicilio no Sistema Único de Saúde - SUS, com inclusão dos procedimentos específicos na tabela de procedimentos do Sistema de Informações Ambulatoriais do SIA/SUS e dá outras providências. Diário Oficial da União, 11 dez 1998; Seção 1.

17. Sales CA, Benedetti GMS, Santos JA, Marcon SS. O impacto do diagnóstico do câncer infantil no ambiente familiar e o cuidado recebido. Rev. Eletr. Enf. [Internet] 2012;14(4) [acesso em 15 nov 2016]. Disponível: https://doi.org/10.5216/ ree.v14i4.15446.

18. de Souza MGG, Gomes AMT. Sentimentos compartilhados por familiares de pacientes oncológicos em tratamento quimioterápico: um estudo de representações sociais. Rev. enferm. UER]. [Internet] 2012;20(2) [acesso em 15 nov 2016]. Disponível: http://www.e-publicacoes.uerj.br/index.php/enfermagemuerj/article/view/4009.

19. Pinto AC, Marchesini SM, Zugno PI, Zimmermann KG, Dagostin VS, Soratto MT. A importância da espiritualidade em pacientes com câncer. Rev. Saúde.Com. [Internet] 2015;11(2) [acesso em 05 ago 2017]. Disponível: http://www. uesb.br/revista/rsc/ojs/index.php/rsc/article/view/263. 